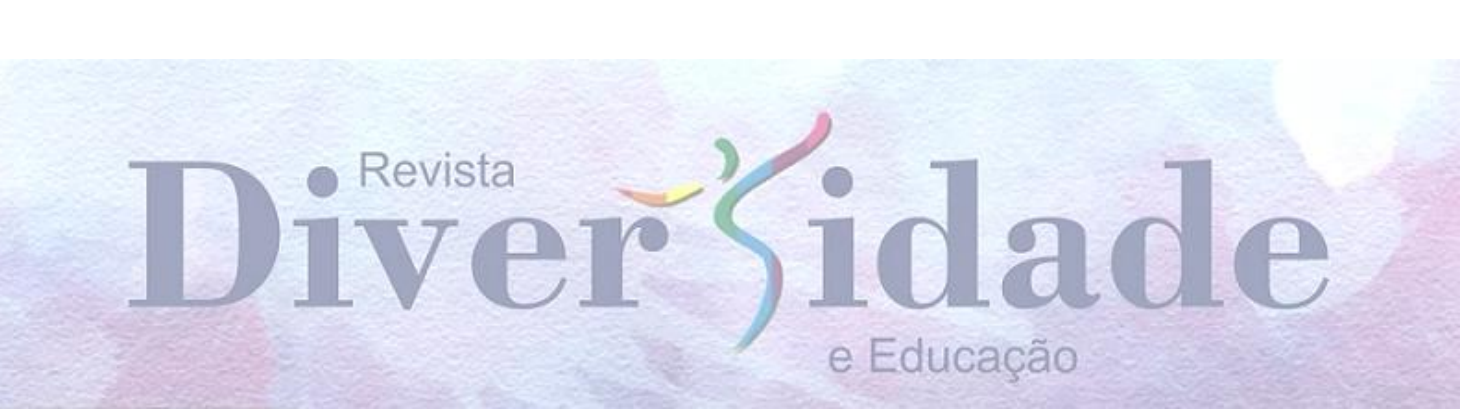

\title{
(DES)CONSTRUÇÃO DO SEXISMO ATRAVÉS DE MÚSICA E LITERATURA
}

\author{
(DES)CONSTRUCCIÓN DEL SEXISMO A TRAVÉS DE LA MÚSICA Y \\ LITERATURA
}

\author{
DECLINING SEXISM THROUGH MUSIC AND LITERATURE
}

\author{
Gisele Martins Ferreira ${ }^{1}$ \\ Andréia Alves Correa da Silva ${ }^{2}$ \\ Angelica do Nascimento Amaral ${ }^{3}$
}

\section{RESUMO}

Devido a grande diferença social dos gêneros, as pessoas do sexo feminino são submetidas a diversos preconceitos baseados na supremacia masculina. O objetivo do presente trabalho é apresentar uma metodologia de problematização do tema com base em uma vivência escolar satisfatória. O tema foi discutido através de músicas populares, com letras misóginas, biografias de personalidades femininas de impacto no seu tempo e textos da literatura de diversos gêneros. Posteriormente, a percepção das/os educandas/os foi exposta por meio de charges e poemas. Concluiu-se que a problematização do sexismo através de abordagens cotidianas auxilia na percepção do silenciamento feminino.

PALAVRAS-CHAVE: Educação em Sexualidade. Sexismo. Contos de fadas.

\section{RESUMEN}

Debido a la gran diferencia social de los géneros, las personas del sexo femenino son sometidas a diversos prejuicios basados en la supremacía masculina. El objetivo del presente trabajo es presentar una metodología de problematización del tema con base en una vivencia escolar satisfactoria. El tema fue discutido a través de canciones populares, con letras misóginas, biografías de personalidades femeninas de impacto en su tiempo y textos de la literatura de diversos géneros. Posteriormente, la percepción de los educandos fue expuesta por medio de caricaturas y poemas. Se concluyó que la problematización del sexismo a través de enfoques cotidianos auxilia en la percepción del silenciamiento femenino.

\footnotetext{
${ }^{1}$ Mestranda em Ensino e História das Ciências e da Matemática.UFABC. Santo André, São Paulo, Brasil

${ }^{2}$ Especialista em Psicopegadogia. FALC, Carapicuiba, São Paulo, Brasil.

${ }^{3}$ Especialista em Práticas reflexivas em Linguística Aplicada. PUC, São Paulo, Brasil.
} 
PALABRAS-CLAVE: Educación en Sexualidad. Sexismo. Cuentos de hadas.

\begin{abstract}
Due to the great social difference of the genders, the female sex people are submitted to diverse prejudices based on the masculine supremacy. The objective of the present work is to present a methodology of problematization of the theme based on a satisfactory school experience. The theme was discussed through popular songs, with misogynistic lyrics, biographies of female personalities of impact in their time and texts of the literature of diverse genres. Subsequently, the students' perception was exposed through cartoons and poems. It was concluded that the problematization of sexism through everyday approaches helps in the perception of female silencing.
\end{abstract}

KEYWORDS: Education in Sexuality. Sexism. Fairy tale.

$$
* * *
$$

\title{
Introdução
}

A representação das princesas de contos de fadas é por si só uma exaltação da hegemonia do papel socialmente aceito para a mulher. Espera-se que a mulher seja bela, educada, caridosa, meiga, tenha habilidade com serviços domésticos (XAVIER, 2011), e mais uma infinidade de aspectos que colocam a mulher em uma posição de submissão ao masculino.

Além de estereótipos de gênero, os contos de fadas carregam em si muitos outros signos que geram paradigmas negativos. Christina Ramalho (2001) aponta que em Cinderela - um dos textos escolhidos para o presente trabalho -, a moça aceita prontamente a sua nova condição de vida após o novo casamento do pai, sendo só liberta pela misericórdia do príncipe. Tem então que conviver com a madrasta, que sempre é tida como a bruxa má em histórias infantis, independentemente de possuir poderes mágicos ou não. As irmãs cruéis são mulheres feias, associando a feiura física com a falta de ética e caráter.

Os signos demonstrados na literatura infanto-juvenil são ainda tão arraigados na nossa sociedade que por vezes vemos os mesmos estereótipos ainda sendo replicados infinitamente em outros meios de expressão artísticas. Dentro da música popular podemos verificar uma "violência simbólica" que sustenta a supremacia masculina e coloca a mulher como objeto sexual ou fadada aos afazeres do lar (SILVA; ANJOS, 2012). A "violência simbólica", termo cunhado por Pierre Bourdieu, prevê uma naturalização do autoritarismo do grupo socialmente dominante sobre o grupo 
dominado (SILVA; ANJOS, 2012). Sendo assim, não há necessidade de o homem se impor como superior, pois já é imposto subjetivamente na sociedade, utilizando-se da diferença anatômica como uma justificativa natural para a divisão social de gêneros (BOURDIEU, 2007).

As mídias aqui utilizadas na intervenção junto aos estudantes são parte das pedagogias culturais que, de forma explícita ou dissimulada, são responsáveis por realizar um processo eternamente inacabado da construção e controle da identidade de gênero do indivíduo (LOURO, 2008). As múltiplas estratégias para o controle da identidade de gênero, especialmente a feminina, sempre tão naturalizadas na escola, demonstram o como ser mulher ou homem e servindo de norte para a "forma correta" de se viver a sexualidade (SABAT, 2013). Contudo, botamos em xeque da necessidade de se manter tal hegemonia nas próximas gerações. Com a finalidade de descontruir a "violência simbólica" do masculino sobre o feminino, a problematização de tais temas nas salas de aula planta uma semente para o questionamento dessa naturalização das diferenças de gêneros.

\section{Desconstruindo o sexismo no chão da escola}

Devido à infinidade de discursos sexistas que incessantemente permeiam nos nossos espaços escolares, seja na fala de discentes e docentes ou nas músicas, que irregularmente ecoam nos corredores, vimos à necessidade de discutir tal tema junto aos alunos. As discussões foram realizadas com turmas de $9^{\circ}$ ano do Ensino Fundamental à $3^{\mathrm{a}}$ série do Ensino Médio.

Sendo a sexualidade notoriamente atribuída à disciplina de Ciências e Biologia, as primeiras intervenções foram feitas nessas disciplinas, visando à introdução do tema com base nas vivências cotidianas. Para tanto, letras de músicas populares foram problematizadas com as turmas, partindo-se de uma letra completa de um funk carioca que abordasse o tema, observando o nível adequado para a faixa etária. Posteriormente, músicas de outros gêneros musicais brasileiros foram problematizadas, a fim de desmitificar a ideia do imaginário popular que somente o funk carioca denigre a imagem feminina e incita a violência contra a mulher.

As mazelas sofridas pelas mulheres na sociedade foram discutidas com base em uma série de textos literários. Sendo apresentada na forma de crônica, a obra Correio Feminino de Clarisse Lispector (NUNES, 2006), onde, informalmente, sob o 
pseudônimo de Helen Palmer, a autora critica a padronização da vida e da estereotipação dos comportamentos femininos da sociedade no pós-guerra (NUNES, 2012). A poesia de Carolina Maria de Jesus (1996) foi utilizada no intuito de demonstrar a lacuna deixada na literatura brasileira, que apresenta somente um recorte de ideias e estéticas muito limitado de um grupo escrevendo para seus pares (MEIHY, 1998), silenciando os discursos dos escritores não hegemônicos. A leitura do conto de fadas Cinderela (GRIM, 2018), em uma versão mais fiel ao original, a fim de apontar o estereótipo feminino naturalizado nesse tipo de texto e o seu impacto para a construção do sexismo desde a infância. Tais textos deram uma visão ampla de diversos tipos de segregações e preconceitos que as mulheres estão sujeitas. Vale ressaltar que as alunas ficaram bastante chocadas ao conhecer o texto da Cinderela numa versão diferente da tão cheia de "máscaras românticas" a qual estamos acostumadas/os.

Posteriormente, o grupo de estudantes realizou produções gráficas e escritas autorais que retratassem a misoginia que observavam no seu cotidiano (exemplo na figura 1). Dezenas de textos foram produzidos e expostos durante mês do Dia Internacional da Mulher, tanto na unidade escolar como na Diretoria de Ensino da cidade.

Figura 1. Charge (A) e poema (B) produzidos pelas/os alunas/os.

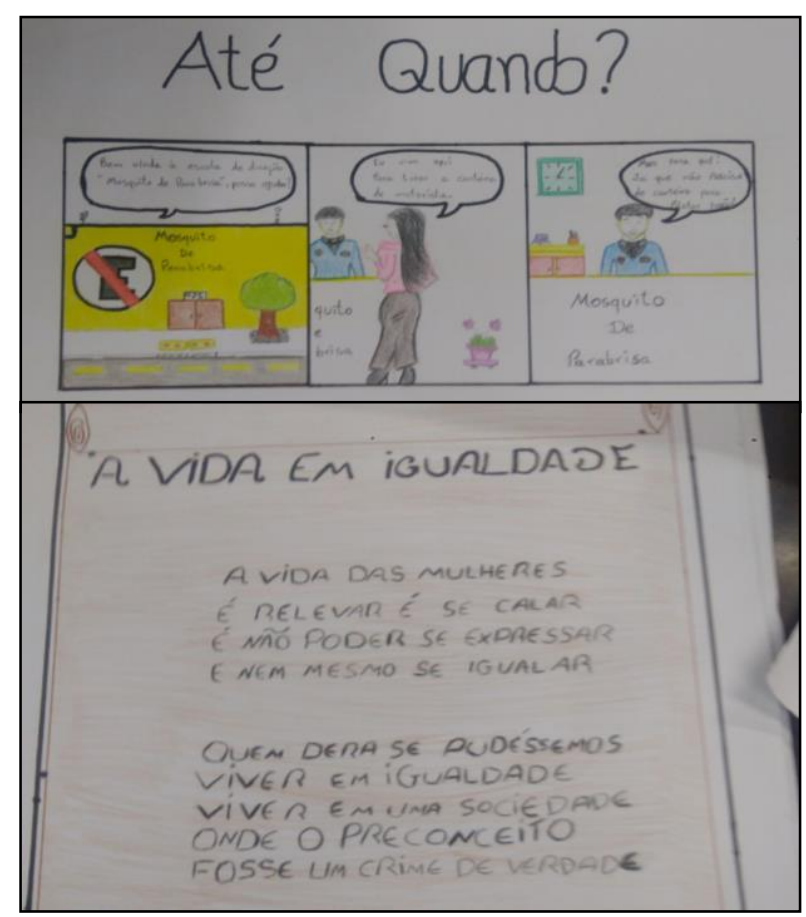

Fonte: Arquivo pessoal. 


\section{Conclusão}

As realidades sociais devem ser problematizadas do ponto de vista da/o aluna/o. Partindo do seu patrimônio cultural e ampliando para novas leituras do mundo. Certamente há entraves institucionais tanto de recursos, quanto a de aceite da comunidade, contudo para uma mudança efetiva na educação devemos acreditar que a mudança é possível e realizar propostas coerentes com a mudança pretendida (CACHAPUZ; PRAIA; JORGE, 2004),. Não deixemos que o silenciamento da sexualidade da mulher, do jovem em formação e das outras expressões de sexualidade não hegemônicas, apontado por Foucault (1988) quando observava o período vitoriano, permaneça vivo ainda no nosso século.

\section{Referências}

BOURDIEU, Pierre. A dominação masculina. Tradução Maria Helena Kühner. 5. ed. Rio de Janeiro: Bertrand Brasil, 2007.

CACHAPUZ, Antonio Francisco; PRAIA, João Félix; JORGE, Manuela. Da educação em ciência às orientações para o ensino das ciências: um repensar epistemológico. Ciência \& educação, v. 10, n. 3, p. 363-381, 2004.

FOUCAULT, Michel. História da sexualidade: A vontade de saber. Rio de Janeiro: Graal. 1988. v.1

GRIM. Cinderela. Disponível em: <https://www.grimmstories.com/pt/grimm_contos/a_gata_borralheira_cinderela>. Acesso em: 24 jan. 2018.

JESUS, Carolina Maria de. Meu estranho diário. São Paulo: Xamã, 1996, p. 151-153.

LOURO, Guacira Lopes. Gênero e sexualidade: pedagogias contemporâneas. Proposições, v. 19, n. 2, p. 17-23, 2008.

MEIHY, José Carlos Sebe Bom. Carolina Maria de Jesus: emblema do silêncio. Revista USP, n. 37, p. 82-91, $1998 . \quad$ Disponível em: <https://www.revistas.usp.br/revusp/article/viewFile/27047/28821>. Acesso em: 11 out. 2018.

NUNES, Aparecida Maria (org.). Correio feminino. Rio de Janeiro, Editora Rocco, 2006

NUNES, Aparecida Maria. Dissimulações de Clarice Lispector. Olho d'água, v. 2, n. 2, 2012. <http://www.olhodagua.ibilce.unesp.br/index.php/Olhodagua/article/view/67>. Acesso em: 11 out. 2018. 
RAMALHO, Christina. Mulheres, princesas e fadas: a hora da desconstrução. Revista Gênero, v. 1, n. 2, 2001. Disponível em: <http://www.revistagenero.uff.br/index.php/revistagenero/article/view/365>. Acesso em: 24 jan. 2018.

SABAT, Ruth. Só as bem quietinhas vão casar. MEYER, Dagmar; SOARES, Rosângela. Corpo, gênero e sexualidade. Porto Alegre: Mediação, p. 95-106, 2013.

SILVA, Maria Veruska da. ANJOS, Edjânia Pereira dos. Dominação masculina: a violência simbólica contra a mulher nas letras de músicas brasileiras. In: $17^{\circ}$ ENCONTRO NACIONAL DA REDE FEMINISTA NORTE E NORDESTE DE ESTUDOS E PESQUISA SOBRE A MULHER E RELAÇÕES DE GÊNERO. 2012

XAVIER FILHA, Constantina. Era uma vez uma princesa e um príncipe...: representações de gênero nas narrativas de crianças. Revista Estudos Feministas, Florianópolis, v. 19, n. 2, p. 591-603, agos. 2011. Disponível em: <https://www.jstor.org/stable/24327959>. Acesso em: 24 jan. 2018. 